University of Nebraska - Lincoln

DigitalCommons@University of Nebraska - Lincoln

Civil and Environmental Engineering Faculty

Publications

Civil and Environmental Engineering

2015

Dynamic strength of a modified W-beam BCT trailing-end termination system

\author{
Cody S. Stolle \\ University of Nebraska-Lincoln, cstolle2@unl.edu \\ John D. Reid \\ University of Nebraska - Lincoln, jreid@unl.edu \\ Ronald K. Faller \\ University of Nebraska - Lincoln, rfaller1@unl.edu \\ Mario Mongiardini \\ University of Nebraska - Lincoln
}

Follow this and additional works at: https://digitalcommons.unl.edu/civilengfacpub

Stolle, Cody S.; Reid, John D.; Faller, Ronald K.; and Mongiardini, Mario, "Dynamic strength of a modified Wbeam BCT trailing-end termination system" (2015). Civil and Environmental Engineering Faculty Publications. 114.

https://digitalcommons.unl.edu/civilengfacpub/114

This Article is brought to you for free and open access by the Civil and Environmental Engineering at DigitalCommons@University of Nebraska - Lincoln. It has been accepted for inclusion in Civil and Environmental Engineering Faculty Publications by an authorized administrator of DigitalCommons@University of Nebraska Lincoln. 
Published in International Journal of Crashworthiness 20:3 (2015), PP. 301-315.

doi: 10.1080/13588265.2015.1009308

Copyright (c) 2015 Taylor and Francis. Used by permission.

Submitted August 13, 2014, accepted January 15, 2015

\title{
Dynamic strength of a modified W-beam BCT trailing-end termination system
}

\author{
Cody S. Stolle, ${ }^{1}$ John D. Reid, ${ }^{1}$ Ronald K. Faller, ${ }^{1}$ \\ and Mario Mongiardini ${ }^{2}$
}

\author{
1 Midwest Roadside Safety Facility, University of Nebraska-Lincoln, Lincoln, NE, \\ USA \\ 2 Transport and Road Safety (TARS), University of New South Wales, Sydney, \\ Australia \\ Corresponding author - C. S. Stolle, email csstolle@huskers.unl.edu
}

\begin{abstract}
W-beam systems utilize end-terminal anchorages to develop tension upstream and downstream of an impact event. However, the capacities of the anchorage components under impact loading are not well known. One such W-beam end anchorage system, the Midwest guardrail system (MGS) trailing-end anchorage, was evaluated using three dynamic component tests _ a soil foundation tube pull test, a breakaway cable terminal (BCT) post splitting test, and an MGS end anchorage system pull test. The peak load recorded during a soil foundation tube test was $193 \mathrm{kN}$ at $56 \mathrm{~mm}$ deflection, as measured at the ground line. BCT posts split at loads of 17.8 and $32.9 \mathrm{kN}$. The end-anchorage tensile capacity was $156 \mathrm{kN}$, dissipating $64.7 \mathrm{~kJ}$. Results from the component tests were also used to create and validate nonlinear finite element models of the components in order to be used for future design and analysis of end anchorages.
\end{abstract}

Keywords: W-beam end terminal, MGS end anchorage, breakaway cable terminal (BCT), component test, computer simulation, LS-DYNA 


\section{Introduction}

Most strong-post, W-beam guardrail systems are classified as semirigid barriers, according to the AASHTO classification system [2], which redirects vehicles with a combination of rail tension, rail bending, and post deformation or rotation. End terminals are designed to develop the required tension upstream and downstream of an impact event. In locations in which the end of the guardrail is not located within the clear zone, non-crashworthy end terminations may be utilized, such as derivatives of the breakaway cable terminal (BCT) system. Many guardrail end-terminal systems utilize elements of the BCT end terminal, including a cable anchorage system and one or two breakaway posts $[3,9,10,18,19]$.

The original BCT terminal was first developed in the early 1970 s by researchers at Southwest Research Institute (SwRI) [11] as part of multiple NCHRP projects. The system consisted of two breakaway wood posts (or BCT posts) embedded in soil. A 63-mm diameter hole was drilled through the timber post and parallel to the strong axis of bending to facilitate fracture in a controlled manner and to allow an impacting vehicle to pass through without imposing a sudden deceleration or rapidly changing its trajectory. A cable anchor assembly consisted of swaged end terminations on a 19-mm diameter, $6 \times 19$ wire rope. One threaded end was inserted into the $\mathrm{BCT}$ hole of the end post, and the other was inserted into an anchor bracket attached to the back side of the guardrail between post nos. 1 and 2.

Over time, this general end terminal had evolved in order to meet various crash testing requirements and to improve anchorage capacity. Steel foundation tubes were first introduced in NCHRP Research Digest No. 124 as an alternative foundation for the BCT [6] to enhance the post-soil resistance by distributing the load in a more homogenous manner, while also allowing for easier post replacement if fractured. A compression strut between the tube foundations was first introduced during the development of the eccentric loader terminal (ELT) to maximize the soil resistance by coupling two foundation tubes [7]. Taller guardrail systems, such as the Midwest Guardrail System (MGS) [8], further modified the design by raising the post and altering the BCT hole location.

Although derivatives of the BCT end-anchorage system have been used extensively, the tensile capacity of the modified anchorage is currently unknown. In addition, the force versus deflection behavior of BCT posts inserted in soil foundation tubes has not been 
characterized, and minimal research is available to analyze BCT post splitting and weak-axis fracture. Failure of any anchorage component could lead to catastrophic rail release and vehicle vaulting, pocketing, or rollover. Failures of these critical components were observed in multiple high-severity crash testing efforts [5,16].

Furthermore, computer models of the end-anchorage system have not been validated against test data. Models must be validated to identify potential improvements and predict performance of the anchorage system during special loading conditions. In addition to realistically modelling the end-anchorage strength during simulated impacts, validated models could be used to evaluate potential improvements to end-anchorage systems and may culminate in larger anchorage capacities.

\section{Research objectives and scope}

The research objective of this study was twofold: (1) to identify performance limits of the MGS end-anchorage system and its components in support of determination of the downstream end of the length of need (LON) [1]; and (2) to calibrate and validate a model of the MGS end anchorage system. To fulfil the research objectives, three types of component tests were conducted at the Midwest Roadside Safety Facility (MwRSF) to assess the maximum load, deflection, and energy absorption of critical end-anchorage components: a pull test of a soil foundation tube; a splitting test of a BCT post; and a pull test of an MGS end-anchorage system [12,13]. Component tests were simulated, and validated models of the components were developed.

\section{Description of MGS end anchor}

The MGS end-anchorage system comprises two MGS BCT posts, soil foundation tubes, a cable anchor assembly, guardrail, and a groundline strut, as shown in Figure 1. The MGS BCT posts are installed in steel soil foundation tubes, which are embedded to a depth of $1778 \mathrm{~mm}$. A BCT cable assembly is attached to the post by inserting a swaged end of the cable into the BCT hole and through a bearing plate, and attached to the guardrail using a cable anchor bracket. The guardrail is attached to the BCT posts with a top mounting height of $787 \mathrm{~mm}$. A C-channel groundline strut is used to connect the two soil foundation tubes. 


\section{Soil foundation test}

\subsection{Test setup}

Although many soil foundation tubes remain nearly stationary during longitudinal guardrail impacts, some soil foundation tube movement has been observed. A pull test was conducted on an MGS soil foundation tube, as shown in Figure 2. The top of the tube was reinforced to prevent localized deformation near the loading point. A BCT post was placed in the tube to account for post inertia. A plot of the cable pull force versus horizontal soil foundation tube deflection for both the component test and simulation is shown in Figure 3.

The displacement of the foundation tube at the ground line was measured using a string potentiometer, and an accelerometer mounted at the CG of a $2168-\mathrm{kg}$ rigid surrogate vehicle travelling at an initial speed of $26.0 \mathrm{~km} / \mathrm{h}$ was used to record pull forces. The pull speed was selected based on site layout and vehicle maximum speed constraints.

The pull cable tension increased rapidly to a maximum of 194.7 $\mathrm{kN}$ as the soil foundation tube accelerated and compressed the soil in the pull direction. The tension then decreased to between 80 and 100 $\mathrm{kN}$ as the soil tube deflected and the bogie vehicle slowed, and soil was projected in front of the tube. As more soil was displaced and accumulated in front of the foundation tube, the pull force increased to a second maximum of approximately $187 \mathrm{kN}$, before the bogie vehicle rebounded and the pull force dissipated. The maximum dynamic displacement was $165 \mathrm{~mm}$, and the final permanent set deflection was $73 \mathrm{~mm}$.

Only the displacement at the top of the soil foundation tube was recorded. Thus, a robust moment-angle characterization of the soil foundation tube bogie testing was not possible.

\subsection{Simulation model}

A model of the soil foundation test was created using beam elements and a point mass to represent a wire rope and bogie vehicle. The bogie and wire rope were connected to a rigid, shell-element soil foundation tube attached to longitudinal and lateral nonlinear spring elements at the ground line. The springs were simplified representations of the forces and moments applied to the

Loads and deflections of the test and simulation were similar through a deflection of $102 \mathrm{~mm}$, and the $173 \mathrm{~mm}$ peak displacement 
of the foundation tube compared well with the $165-\mathrm{mm}$ maximum displacement in the test. The average simulated force through 102 $\mathrm{mm}$ of deflection was $115 \mathrm{kN}$, which varied from test data by $5 \%$. Most practical end-anchorage deflections will be limited to deflections substantially less than $102 \mathrm{~mm}$, and soil material properties are highly variable. Therefore, the simplified soil model was determined to be acceptable and validated.

\section{Development of BCT wood material model}

\subsection{Baseline wood model}

Two timber BCT posts are used in each modified W-beam BCT end termination. A baseline wood model was necessary to calibrate the simulation model to test the results. Researchers generated a wood material model based on impact tests of controlled releasing terminal (CRT) posts perpendicular to the strong and weak axes as well as obliquely at approximately $24 \mathrm{~km} / \mathrm{h}$ [4], because no BCT post-insleeve test results were readily available.

Rectangular CRT posts are $152-\mathrm{mm}$ wide by $203-\mathrm{mm}$ deep timber posts installed directly in soil. The CRT posts have two $89-\mathrm{mm}$ diameter transverse holes drilled parallel to the strong axis, one at ground line and one located approximately $390 \mathrm{~mm}$ below ground to facilitate post fracture. BCT posts are similar to CRT posts, except that BCT posts have finishing cuts made on four sides to facilitate installation in a soil foundation tube. Thus, BCT posts are approximately $13 \mathrm{~mm}$ smaller in width and depth compared to CRT posts. In addition, BCT posts utilize a single $64-\mathrm{mm}$ diameter hole located approximately $92 \mathrm{~mm}$ above ground to facilitate breakaway. Despite these geometrical differences, the variations between BCT and CRT post impact forces, displacements, and fracture energies are small, and typically much less than the variability attributable to the wood material alone. Example CRT posts impacted in strong- and weak-axes directions are shown in Figure 4, and plots of CRT strong and weak-axes impact forces with calibrated timber CRT post material models are shown in Figures 5 and 6.

Peak forces in the strong-axis CRT post tests ranged between 34 and $59 \mathrm{kN}$, and peak forces in the weak-axis post tests ranged between 34 and $46 \mathrm{kN}$. Post fractures dissipated an average of 1.77 and $1.93 \mathrm{~kJ}$ of energy perpendicular to strong and weak axes, respectively. Strong axis and weak-axis CRT fracture energies were 
similar because each fracture was characterized by local fibre rupture and occurred through approximately the same cross section.

Simulated peak forces for the nominal wood model were $35 \mathrm{kN}$ in the strong-axis direction and $22 \mathrm{kN}$ in the weak-axis direction. Energies dissipated in strong- and weak-axes directions of the nominal wood material model were 2.8 and $1.5 \mathrm{~kJ}$, which were $46 \%$ higher and $16 \%$ lower than the corresponding average physical test energies, respectively. The wood model with 50\% higher yield strength more closely matched peak CRT impact forces, but energies dissipated were less accurate than the nominal material values. Simulated fracture of the wood post models occurred via element erosion, as shown in Figure 7. Because effective plastic strain does not differentiate between tension and compression, elements were eroded on both sides of the post in both strong- and weakpost fractures, which reduced peak forces and total energy dissipation.

\subsection{BCT longitudinal splitting test}

Sometimes, longitudinal splitting is observed in BCT posts used to anchor W-beam systems in full-scale crash tests and in some realworld crashes. Researchers attempted to characterize BCT post splitting by attaching an eccentric loading device to the front face of a $\mathrm{BCT}$ post embedded in a rigid foundation tube, and impacting the eccentric loading device with a 1590-lb (721-kg) bogie vehicle travelling approximately at $24 \mathrm{~km} / \mathrm{h}$. The impact speed was selected to ensure post fracture without excessive dynamic inertial effects. The test setup and test results are shown in Figure 8. Results from the bogie tests and simulations were plotted and compared, as shown in Figure 9. Details of the simulations are provided in subsequent sections.

The posts in test nos. BCTRS 1 and BCTRS 2 split into two pieces at loads of 17.8 and $32.9 \mathrm{kN}$, respectively. Cracking predominantly occurred in the vertical direction through delamination along the summerwood (rings), dissipating 2.1 and $2.9 \mathrm{~kJ}$, respectively. Splitting occurred at a deflection of 107 and $97 \mathrm{~mm}$ in test nos. BCTRS 1 and BCTRS 2, respectively, and impact forces related to bending and torsion were approximately 80\% higher in test no. BCTRS 2 than in test no. BCTRS 1 . The differences in force and energy levels were largely attributed to natural wood variability.

An approximate BCT splitting load of $32 \mathrm{kN}$ was calculated by assuming only torsion contributed to post splitting through the postto-rail attachment hole. The weak axis fracture load of BCT posts was 
estimated by linearly scaling the weak-axis impact force of CRT posts by a ratio of the weak-axis section modulus.

\subsection{Modelling BCT post splitting}

Models of the BCT posts were created by replicating BCT geometry using solid elements and using the CRT wood material model. An automatic surface-to-surface contact type with a tiebreak option was used to conjoin two parts of the BCT post where splitting was expected. A linear damage model combined with a critical crack tip opening displacement of $4 \mathrm{~mm}$ was determined to the most accurate method of representing splitting. Simulation results from the BCT post splitting tests are shown in Figure 9.

The simulated post using nominal wood properties split at a load and bogie displacement of $15 \mathrm{kN}$ and $127 \mathrm{~mm}$, respectively, and had a splitting total energy dissipation of $2.2 \mathrm{~kJ}$. The nominal wood simulation compared favorably with test no. BCTRS 1 . The post with $50 \%$ stronger yield strength began to split at a load and bogie displacement of $17 \mathrm{kN}$ and $109 \mathrm{~mm}$, respectively. However, the split arrested, and the post fractured at the ground line. A smaller crack tip opening displacement may be necessary to model stiffer posts subjected to vertical splitting.

A modulus of stiffening was defined as the linear best fit line extending between the end of the inertial force spike and the peak fracture force. This modulus was to evaluate the posts' combined bending and twisting resistance. Nominal and increased wood strength simulations and test no. BCTRS 1 had similar moduli of $0.082,0.107$, and $0.082 \mathrm{kN} / \mathrm{mm}$, respectively.

\subsection{Discussion of wood material properties}

Timber posts demonstrated significant variability and a large standard deviation of test results, as shown in Figures 6 and 7. Wood materials have strong, tensile fibres embedded in a brittle, cellular, porous, low-strength matrix [15]. Moreover, each wood post has a unique fibre orientation, since wood fibres propagate radially from the center of the tree (heartwood) radially. In addition, the outer wood fibres (springwood) are softer than the heartwood fibres which have lower moisture content and denser wood material. Knots, or tree branch locations, tend to be significantly stronger and denser than the surrounding material. The highly heterogeneous material behavior, significant variability of the strength of the tensile fibres 
and cellular matrix, and geometrical effects due to post cut location contribute to variations in physical testing strength results. Moreover, it is nearly impossible to predict the differences in post energy absorption, fracture force, and stiffness (i.e., effective Young's modulus), prior to testing.

Simulation models of wood generally utilize homogenous materials. Attempts to characterize wood with orthotropic materials have proven difficult because the stiffness of the cellular matrix is several orders of magnitude less than the stiffness of the fibres themselves (e.g., 14,15). In addition, many of these material models are unstable in dynamic, multi-axial impact problems in which the wood material fractures [20].

Multiple wood post models were evaluated using estimates for material properties based on recommended material properties [14]. Several material models were studied, including plastic kinematic, piecewise linear, orthotropic, and an isotropic-elastic with plastic hardening and failure. Of these material models, the piecewise linear material was determined to be the most stable and accurate.

Model results shown in Figures 5 and 6 were optimized for energy absorption and peak force. By increasing the peak force prior to post fracture, the energy absorbed during a strong-axis impact rapidly diverged from the limits observed in physical testing. Decreasing the fracture strength led to more rapid post fractures and a substantial decrease in the correlation of weak-post impact energy absorption. During post bending, compression-side element deletion was the most likely source of divergence between test and model results. Thus, the proposed model is deemed to be acceptable for modelling BCT posts.

\section{Evaluation of MGS end-anchorage capacity}

\subsection{Motivation and test setup}

Researchers were able to successfully characterize the movement of BCT soil foundation tubes as well as the torsional splitting load of timber BCT posts pulled downstream by guardrail tension. Subsequent component models successfully modelled the critical behaviors of these components, and differences between test and component performances were identified. A final physical test of the MGS anchorage system was desired to determine the tensile capacity of the anchor during vehicle impact with a longitudinal barrier, and to provide an assessment of the entire MGS end-anchorage system 
computer simulation model. It was determined that the best method to evaluate the capacity of the end anchorage was to simulate an increase in longitudinal guardrail tension until the end anchorage failed.

A short MGS end-anchorage system was constructed with soil foundation tubes connected with a groundline strut, two BCT posts installed in the soil foundation tubes, and a 7.62-m long $\mathrm{W}$-beam rail element attached to the BCT posts. One additional W152 x 13.3 steel post with a 305-mm deep blockout was also used to support the guardrail segment. A BCT anchor cable was attached to the W-beam guardrail with a cable anchor bracket, and the other end of the anchor cable was passed through one BCT post's transverse hole and connected to a BCT bearing plate adjacent to the BCT post. A tension load cell was installed in line with the BCT cable. A 43-m long pull cable was attached to one end of the guardrail section, and the other end was attached to a 2168-kg rigid-frame bogie vehicle used to apply tension to the rail.

\subsection{Test no. DSAP 1 results}

The 2168 -kg rigid-frame bogie vehicle was propelled to $40 \mathrm{~km} / \mathrm{h}$, tensioning the 43-m long pull cable attached to the upstream end of the guardrail. Sequential images of the test and simulation are shown in Figure 10. A plot of the BCT cable tension and end-post soil foundation tube displacement is shown in Figure 11. Test and simulation results for all component tests are summarized in Table 1.

As the bogie accelerated, the pull cable tension increased slowly until the cable became nearly straight. The test official start time (i.e., time zero) was selected as the moment the rate of pull cable tension rise increased sharply. Shortly after time zero, the soil tube deflected to approximately $11 \mathrm{~mm}$, and the second BCT post cracked near the ground line. At approximately $70 \mathrm{~ms}$, the end BCT post fractured at a deflection of approximately $23 \mathrm{~mm}$ and the end BCT post was lifted into the air by the anchor cable and pulled downstream with the bogie vehicle and guardrail. The second BCT post subsequently fractured and rotated around the embedded base, and came to rest approximately $0.3 \mathrm{~m}$ from the second soil foundation tube. The end soil foundation tube rebounded back to within $4 \mathrm{~mm}$ of its original position at the conclusion of the test, as determined by string pot data. After the test, no soil gap was recorded for either soil foundation tube because loose soil fell into 
the void behind the tube as it deflected. The total energy dissipated during the test was $64.7 \mathrm{~kJ}$.

The maximum BCT cable force recorded in the component test was approximately $154 \mathrm{kN}$. The nominal breaking load for a $19-\mathrm{mm}$ diameter, $6 \times 19$ wire rope is approximately $200 \mathrm{kN}$. This result indicates that the BCT cable anchor is optimized for the maximum load sustained by the MGS end anchorage.

Between 1.3 and $9.7 \mathrm{~mm}$ of soil tube deflection, a linear- elastic soil stiffness of $7.67 \mathrm{kN} / \mathrm{mm}$ was calculated. The unloading linearelastic stiffness was $10.27 \mathrm{kN} / \mathrm{mm}$, calculated between 20 and $15 \mathrm{~mm}$ during rebound.

\subsection{Simulation model}

The simulation model of the MGS end anchorage replicated the geometry of the wood posts, soil foundation tubes, BCT cable assembly, guardrail, and groundline strut, as shown in Figure 12. Based on observations of previous full-scale guardrail crash tests, the soil foundation tubes were constrained to prevent translation or axial twisting. Soil forces were modelled using pairs of nonlinear springs with varying loading and unloading stiffnesses attached to each of the four sides of each foundation tube. MGS BCT posts were modelled with solid elements, and the BCT cable was modelled with beam elements. A modified cable material was based on the properties of a 19-mm, $3 \times 7$ wire rope [17]. A summary of the model and validated simulation components is shown in Table 2.

Although the pull cable used in the test was approximately $43 \mathrm{~m}$ long, the simulated cable was shortened to $2438 \mathrm{~mm}$ for simplicity. During testing, an additional vehicle is used to accelerate the bogie vehicle, and may require up to $20 \mathrm{~s}$ to accelerate the bogie vehicle to the desired speed. The bogie vehicle is then released and is freewheeling prior to impact. The computational time required to model this process is excessive, which led researchers to model a shorter cable length. Unfortunately, the more gradual rise in pull cable tension associated with straightening the cable and lifting it off of the ground, as well as the linear elastic compliance of the pull cable, could not be replicated using this method. Thus, simulation events occurred sooner than test events. Accounting for the effect of vertical sag, long-distance cable catenary shape, and simulation start timing, the difference between effective test and simulation start times was approximately $26 \mathrm{~ms}$. 
At approximately $20 \mathrm{~ms}$, a crack initiated in the second BCT post, and at $30 \mathrm{~ms}$, the end BCT post fractured. During crack propagation, the cable anchor tension rose to nearly $222 \mathrm{kN}$, but dropped after the fractured post portion was projected downstream. The second BCT post completely fractured by $40 \mathrm{~ms}$, and was pulled downstream with the deformed guardrail.

The maximum simulated horizontal displacement of the end soil foundation tube was $26 \mathrm{~mm}$. The displacement of the soil tube at maximum force, or 'quasidynamic' maximum displacement, was 24 $\mathrm{mm}$, which differed from the test by $4.4 \%$. Simulated large simulated cable tension exceeded the elastic limit of the 19-mm diameter, $6 \mathrm{x}$ 19 BCT cable anchor wire rope, which caused the rope to plastically deform. This may have been the result of scaling the material properties of a 19-mm diameter, 3x7 wire rope to represent a $6 \times 19$ BCT cable wire rope, which may have overestimated the plastic modulus of the wire rope.

In the simulation, the total energy dissipated by the endanchorage fracture was $61.6 \mathrm{~kJ}$, which differed from the test by $4.9 \%$. A significant difference in dissipated energy between test and simulation may be related to elastic energy storage in the actual pull cable compared to the simulated pull cable. This difference may account for as much as $10.4 \mathrm{~kJ}$ between test and simulation. Therefore, it was determined that the baseline model of the downstream end anchorage accurately predicted the load and stiffness observed in the test, and was therefore validated.

Test no. DSAP 2 was also simulated using the stronger wood material. Differences in fracture times, loads, energy dissipated, and end-post soil foundation tube displacements compared to the nominal wood material simulation were minimal.

A summary of all of the component tests and related simulations is shown in Table 1.

\section{Discussion}

Universally accurate wood post material models have historically proved elusive. It may be necessary to adapt multiple wood material models for different applications. The nominal wood post yield stress underpredicted weak axis peak loads, which suggested that the endanchorage model will likely provide a conservative estimate of end anchorage robustness. Alternatively, the nominal strength model accurately predicted fracture and splitting energies and would be an excellent candidate for assessing end anchorage limits during high- 
severity impact simulations. Simulated BCT posts with the increased yield strength better predicted peak loads, but at the expense of prematurely fracturing when loaded in the weak axis. The stronger wood material might be better suited for assessing performance of end terminals subjected to impacts with small cars. Different wood material models may be appropriate for other timber components, such as CRTs, round wood posts, or blockouts.

The soil stiffnesses calculated from the soil foundation tube pull test was approximately half that of the end-anchorage pull test. This finding may be related to the strut and yoke assembly used in the pull test to increase the rigidity of the end-anchorage system, which facilitated load transfer between both soil foundation tubes. In addition, the BCT cable was skewed with respect to the end foundation tube, and was parallel with the direction of the foundation tube displacement in test no. MGSEA 1.

\section{Summary and conclusions}

Components of the MGS end anchorage were tested with surrogate vehicles at MwRSF to develop validated models of an MGS trailingend anchorage system. Three types of tests were conducted: a pull test of a soil foundation tube; a splitting test of a BCT post; and a pull test of an MGS end-anchorage system. The maximum load applied to a soil foundation tube was $193 \mathrm{kN}$ at $56 \mathrm{~mm}$ of soil foundation tube deflection, as measured at the ground line. The soil foundation tube experienced a $165 \mathrm{~mm}$ maximum dynamic deflection, and a permanent set deflection of approximately $109 \mathrm{~mm}$. Two MGS BCT posts split into two pieces when eccentric lateral loads transmitted through the bolt at the post-to-rail connection reached 17.8 and 32.9 $\mathrm{kN}$, respectively. The maximum load and energy absorption of an end-anchorage system was determined to be $154 \mathrm{kN}$ and $64.7 \mathrm{~kJ}$, respectively.

Results from the component tests were used to create and validate models of the BCT posts and soil resistance of the soil foundation tubes. Historical wood post data using MGS CRT posts placed in rigid sleeves were used to validate a wood material model for the timber BCT posts. Modelling the soil foundation tubes with rigid shell element parts constrained against translation and twisting with nonlinear soil force displacement curves was determined to be acceptable. Elastic soil stiffness, maximum foundation tube displacement, and peak forces of the test and simulation compared favorably. The estimated splitting load of the BCT posts was 
determined to be at least $32 \mathrm{kN}$. The MGS end anchorage was validated against component testing, and dissipated energy and end soil tube displacement were accurate to within 10\%.

Therefore, the simulation models of the MGS end anchorage were recommended for use in longitudinal guardrail impact simulations. In addition, the practical maximum load that the MGS end anchorage can sustain prior to wood post fracture is approximately $156 \mathrm{kN}$ by assuming that the BCT cable anchor load mimics the total rail load. An appropriate end-anchorage design load would be approximately $133 \mathrm{kN}$, based on the observation that both BCT posts fractured at approximately the same time, and anchor loads during testing and real-world end-anchorage failures may result in catastrophic rail release from all posts between impact and the end anchorage.

Acknowledgments - The authors wish to acknowledge Midwest Roadside Safety Facility personnel for constructing, conducting, and analyzing the component tests. Individuals deserving recognition include Jim Holloway, Bob Bielenberg, Scott Rosenbaugh, Karla Lechtenberg, Shaun Tighe, and Curt Meyer. The research was conducted at the Midwest Roadside Safety Facility, University of Nebraska-Lincoln, USA.

Disclosure statement - No potential conflict of interest was reported by the authors.

Funding - The researchers would like to thank the Wisconsin Department of Transportation and Erik Emerson [grant number TPF-5(193) Suppl.\#28] for funding this research study.

\section{References}

[1] Manual for Assessing Safety Hardware (MASH), American Association of State Highway and Transportation Officials (AASHTO), Washington, DC, 2009.

[2] Roadside Design Guide, American Association of State Highway and Transportation Officials (AASHTO), Washington, DC, 2011.

[3] D. Alberson, W. Menges, and R. Haug, Guardrail testing - modified eccentric loader terminal (MELT) at NCHRP 350 TL-2, Report No. NETCR-35, Texas Transportation Institute, Texas A\&M University, College Station, TX, 2002.

[4] S. Arens, D. Sicking, and R. Faller, Investigating the use of a new universal breakaway steel post, Research Report No. TRP-03-281-09, Midwest Roadside Safety Facility, University of Nebraska-Lincoln, Lincoln, NE, 2009. 
[5] R. Bielenberg, R. Faller, and D. Sicking, Midwest guardrail system for long span culvert applications, Transp. Res. Rec. 2025 (2007), pp. 3-17.

[6] M. Bronstad, A Modified Foundation for Breakway Cable Terminals, NCHRP Research Results Digest 124, Washington, DC, 1980.

[7] M. Bronstad, J. Mayer, Jr., and J. Hatton, Crash test evaluation of eccentric loader guardrail terminals, Transp. Res. Rec. 1065 (1986).

[8] R. Faller, K. Polivka, and B. Kuipers, Midwest guardrail system for standard and special applications, Transp. Res. Rec. 1890 (2004), pp. 19-33.

[9] K. Mak, R. Bligh, and H. Ross, Jr., Slotted rail guardrail terminal, Trans. Res. Rec. 1500 (1995).

[10] J. Mayer, Full-Scale Crash Evaluation of a Fleat Median Terminal System Test FMT-3M, Southwest Research Institute, San Antonio, TX, 2001.

[11] J. Michie and M. Bronstad, Breakaway Cable Terminals for Guardrails and Median Barriers, NCHRP Research Results Digest 84, Washington, DC, 1976.

[12] M. Mongiardini, R. Faller, J. Reid, and D. Sicking, Dynamic evaluation and implementation guidelines for a nonproprietary $\mathrm{W}$-beam guardrail trailing-end terminal, J. Trans. Res. Rec. 2377 (2014), pp. 61-73.

[13] M. Mongiardini, R. Faller, J. Reid, D. Sicking, C. Stolle, and K. Lechtenberg, Downstream anchoring requirements for the Midwest guardrail system, Midwest Research Report No. TRP-03-279-13, Midwest Roadside Safety Facility, University of Nebraska-Lincoln, Lincoln, NE, 2013.

[14] Y. Murray, Manual for LS-DYNA wood material model 143, Report No. FHWA-HRT-04-097, APTEK, Inc., Colorado Springs, CO, 2007.

[15] Y. Murray, J.D. Reid, R.K. Faller, R.W. Bielenberg, and T.J. Paulsen, Evaluation of LS-DYNA wood material model 143, Research Report No. FHWA-HRT-04-096, APTEK, Inc., 2005.

[16] J. Reid, B. Kuipers, and D. Sicking, Impact performance of W-beam guardrail installed at various flare rates, Int. J. Impact Eng. 36 (2009), pp. 476-485.

[17] J. Reid and C. Stolle, Development of a wire rope model for cable guardrail simulation, IJ Crash 16 (2011), pp. 331-341. doi 10.1080/13588265.2011.5866o9\#.U-u492NNiNI.

[18] H. Ross, Jr., W. Menges, and D. Bullard, NCHRP Report 350 Compliance Testing of the ET-2000, Texas Transportation Institute, Texas A\&M University, College Station, TX, 2005.

[19] D. Sicking, J. Reid, and J. Rohde, Development of a sequential kinking terminal for W-beam guardrails, Transp. Res. Rec. 1647 (1998), pp. 8996.

[20] C.S. Stolle, J.D. Reid, R.W. Bielenberg, R.K. Faller, D.L. Sicking, and K.A. Lechtenberg, Extending TL-2 short radius guardrail to larger radii, Final Report to the Wisconsin Department of Transportation, MwRSF Research Report No. TRP-03-296-14, Midwest Roadside Safety Facility, University of Nebraska-Lincoln, Lincoln, NE, 2014. 


\section{Figures}
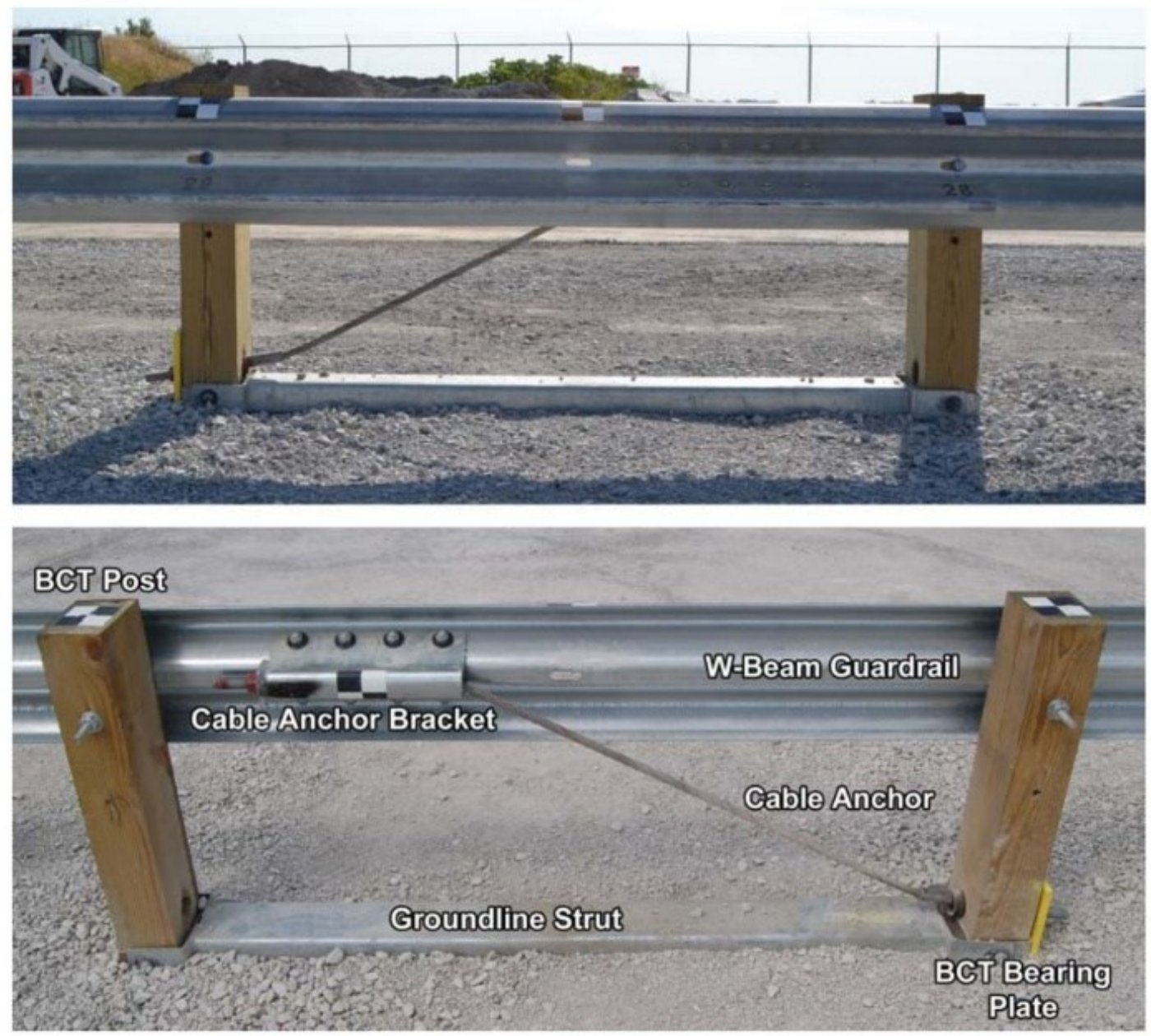

Fig. 1. MGS end-anchorage system. 

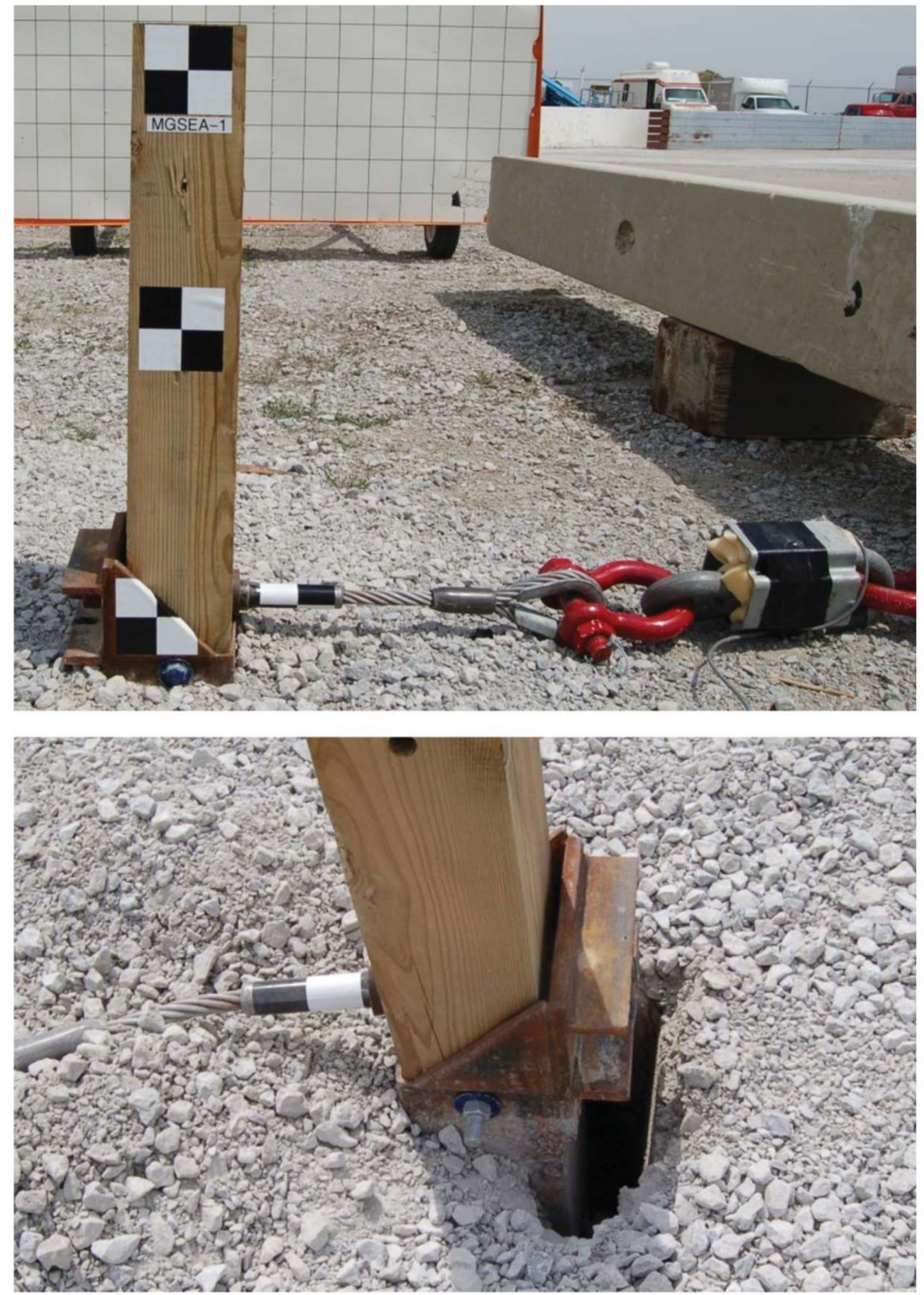

Fig. 2. Soil foundation tube pull test setup, before and after test. 


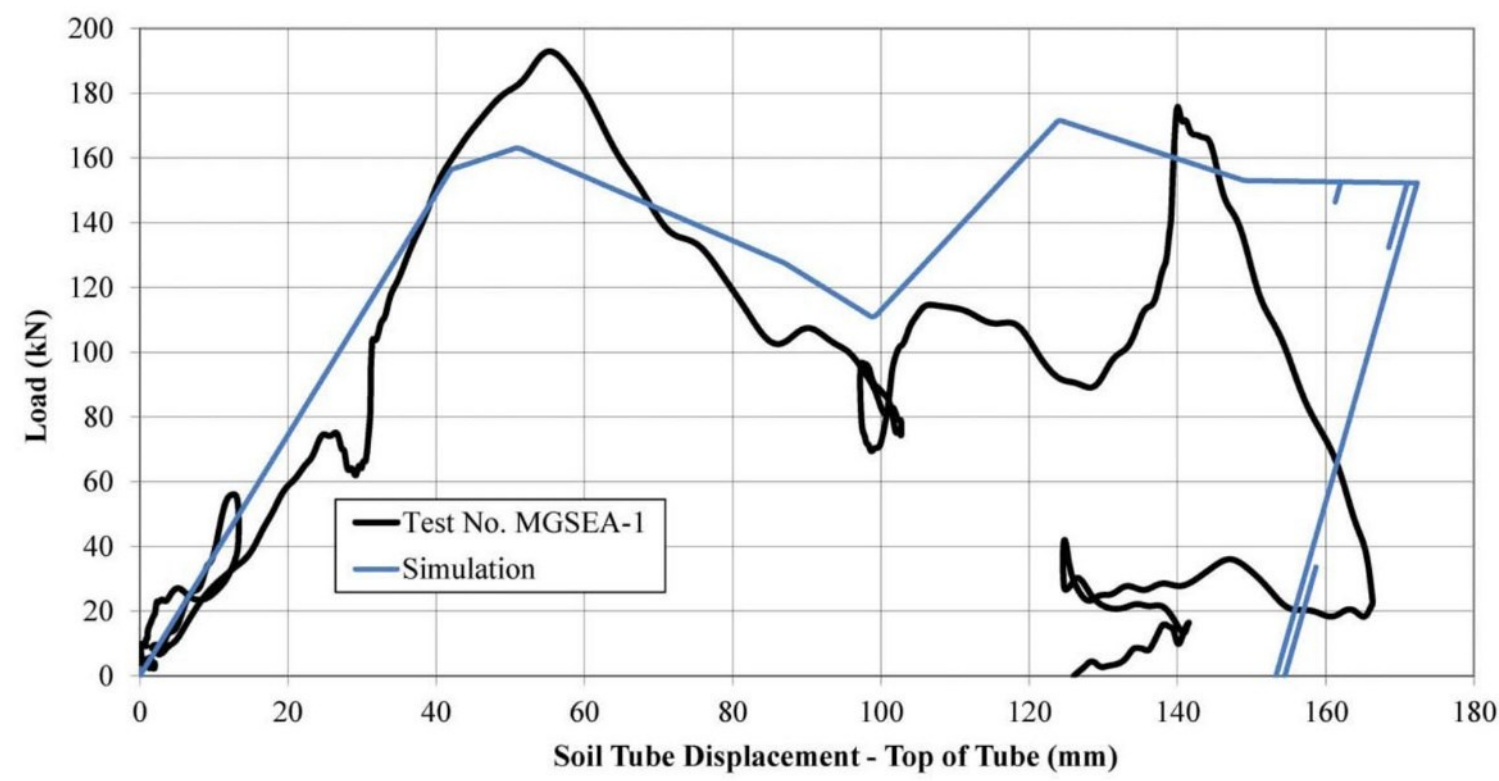

Fig. 3. Pull cable force versus top of soil tube deflection.
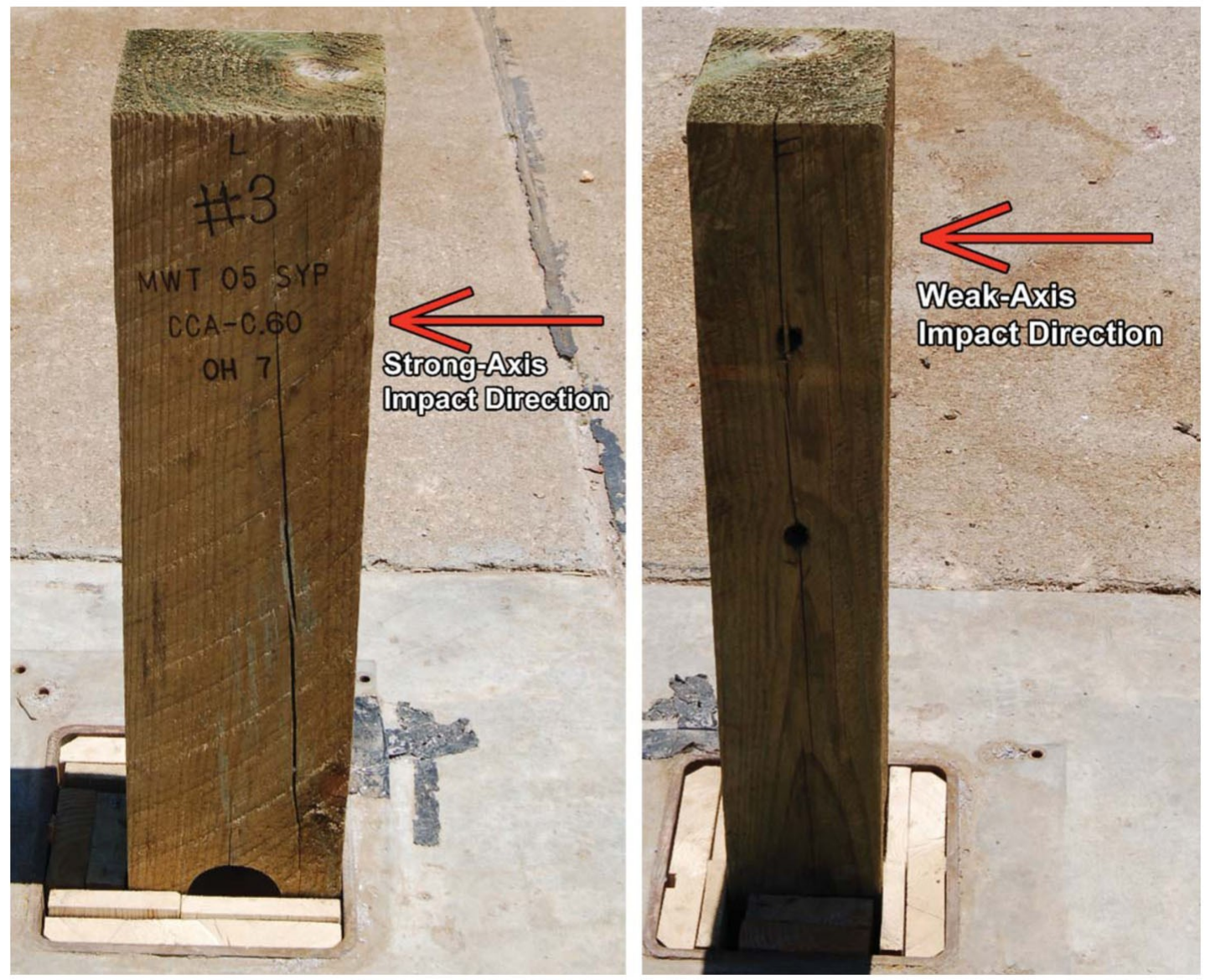

Fig. 4. Model CRT and post impact configurations. 

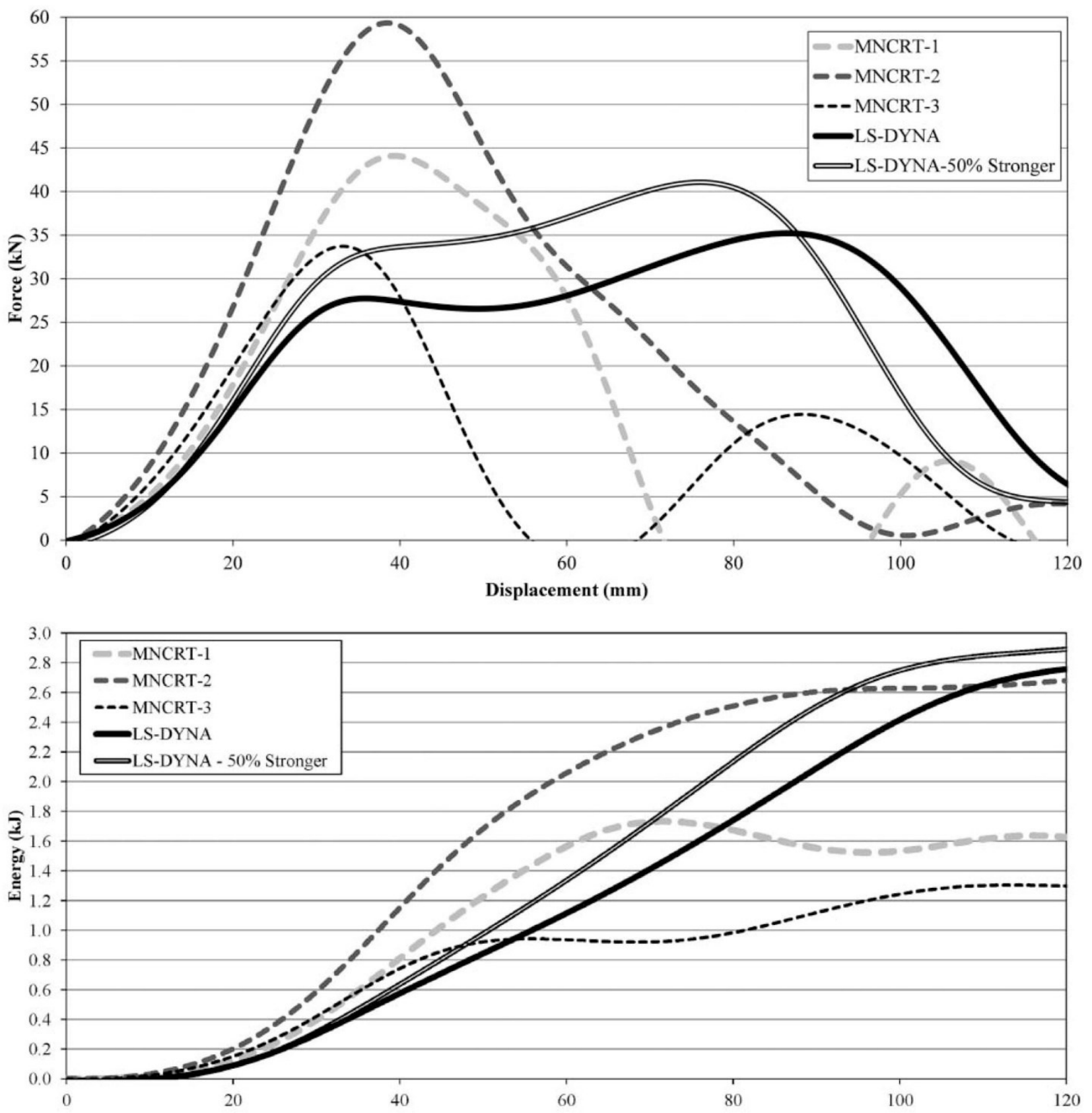

Displacement (mm)

Fig. 5. Strong-axis CRT impact, tests and simulation. 

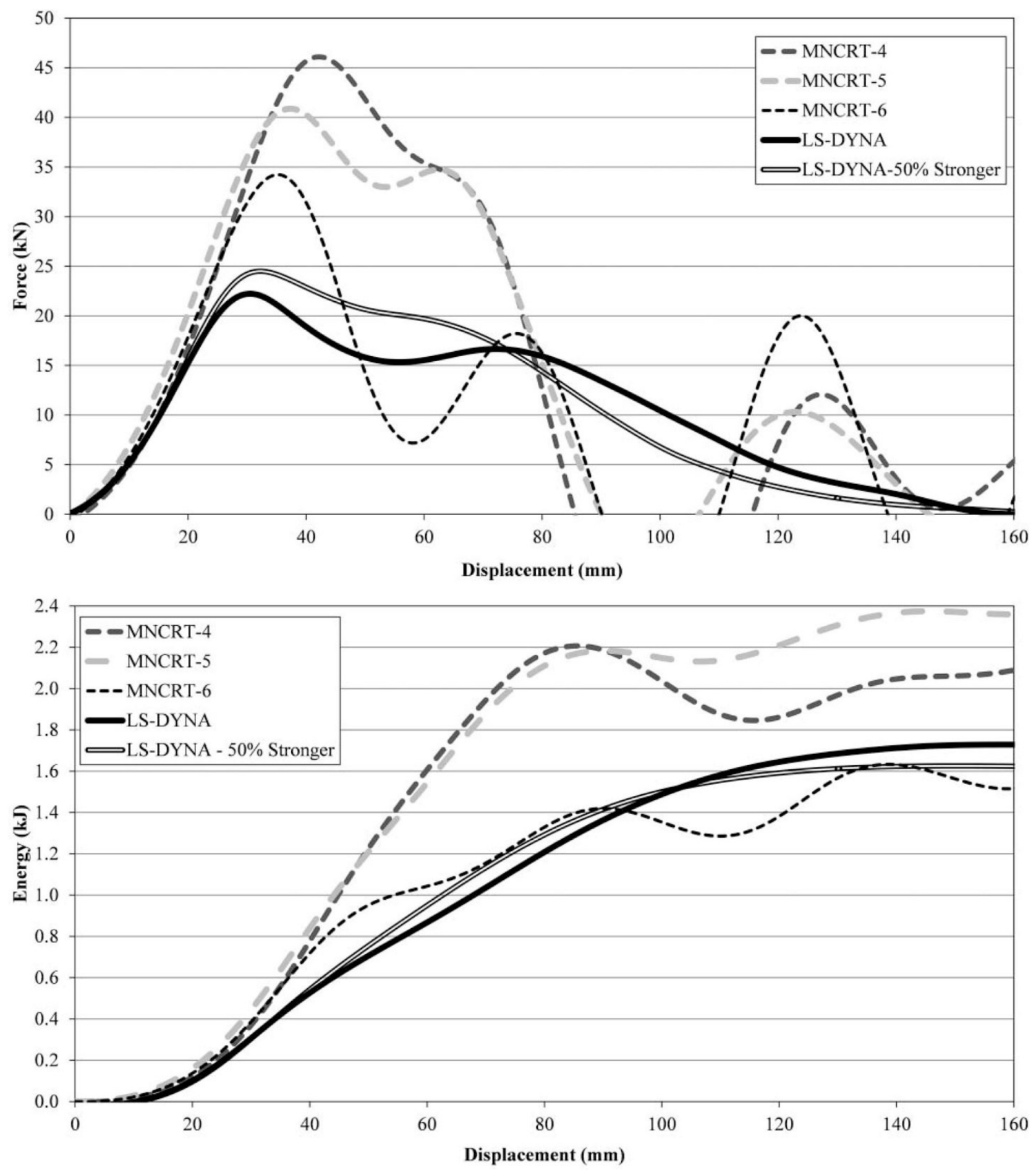

Fig. 6. Weak-axis CRT impact, tests and simulation. 
(a)
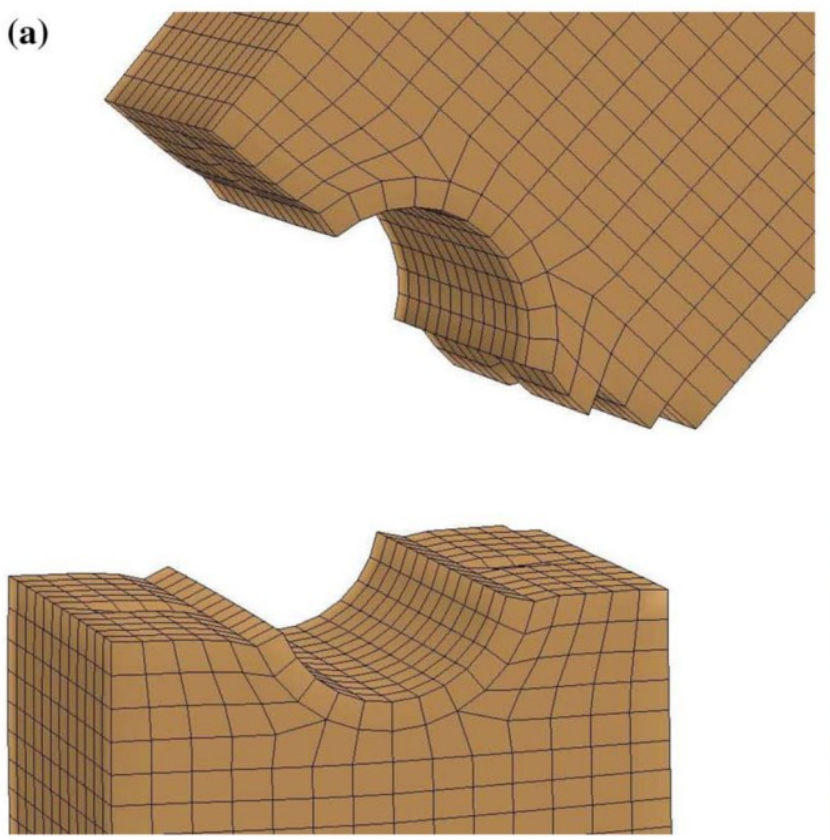

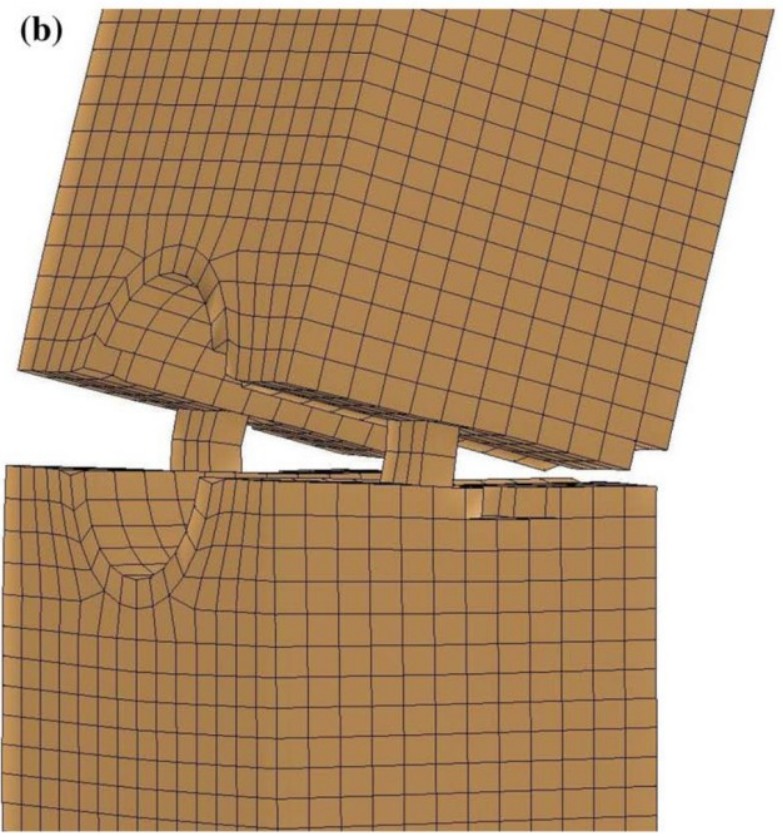

Fig. 7. Strong- and weak-axes CRT simulations: (a) strong axis and (b) weak axis. 

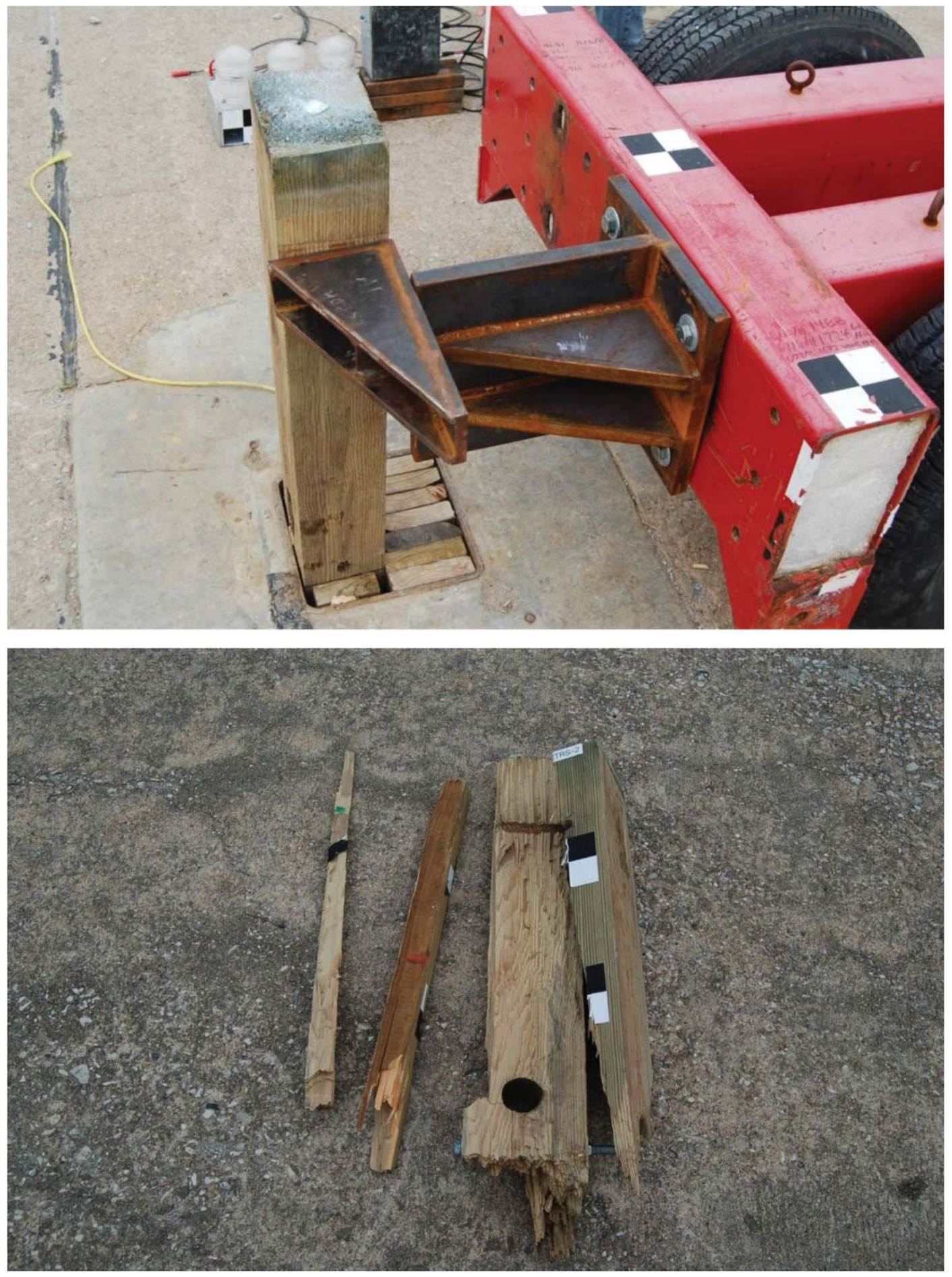

Fig. 8. Post splitting bogie component testing, before and after impact. 

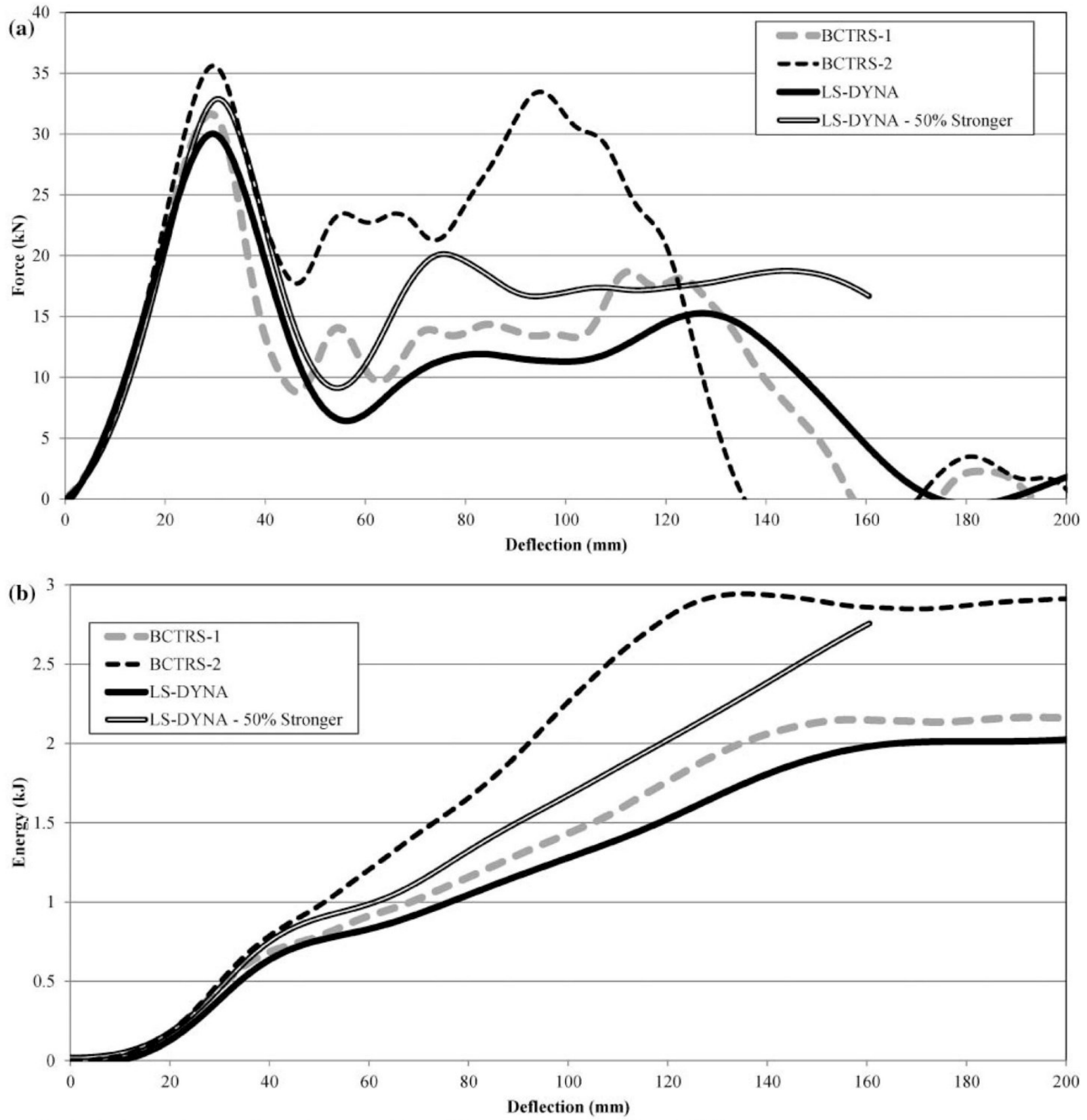

*NOTE: Crack arrested and post fractured near ground line at $160 \mathrm{~mm}$ deflection in simulation with $50 \%$ stronger wood

Fig. 9. Force versus deflection and energy versus deflection of splitting BCT post, tests and simulation. 

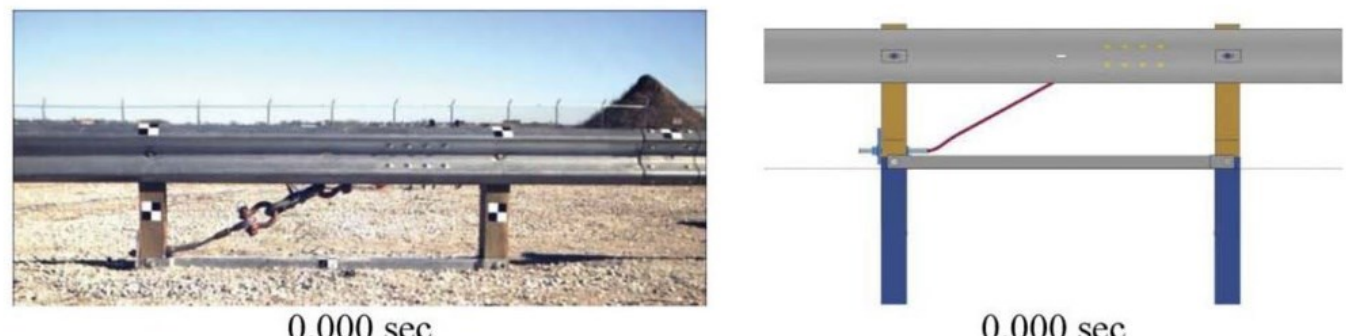

$0.000 \mathrm{sec}$
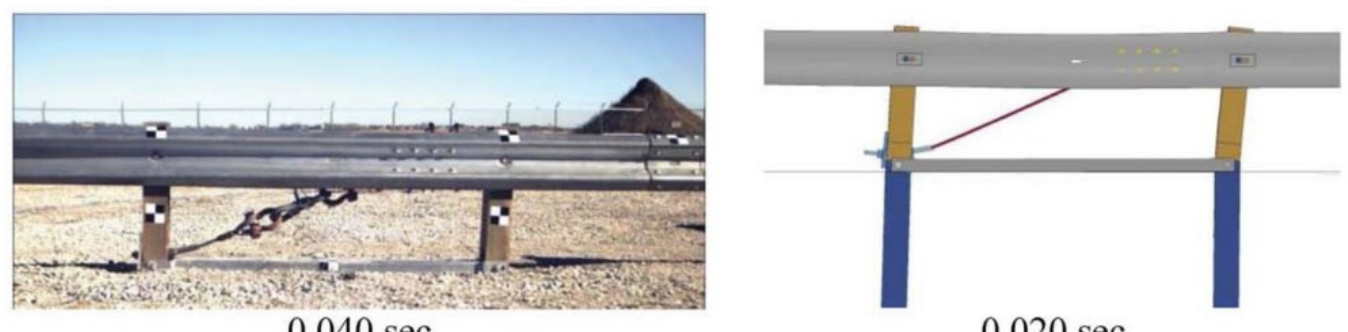

$0.040 \mathrm{sec}$

$0.020 \mathrm{sec}$

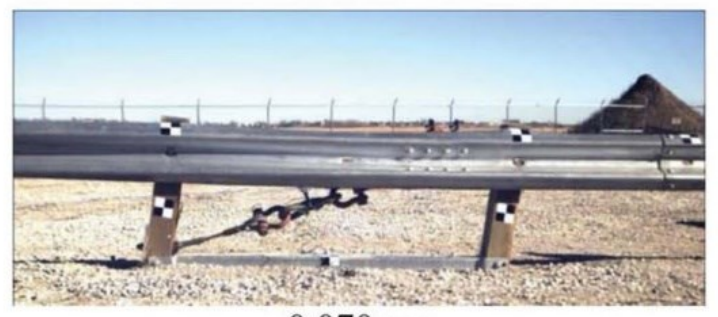

$0.070 \mathrm{sec}$

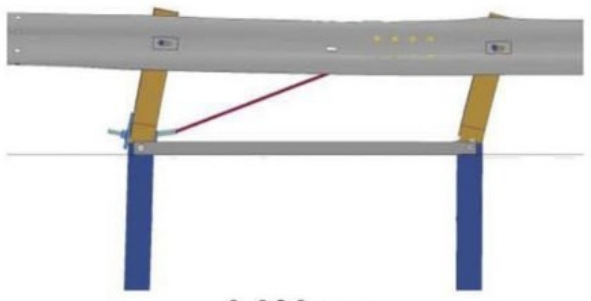

$0.030 \mathrm{sec}$

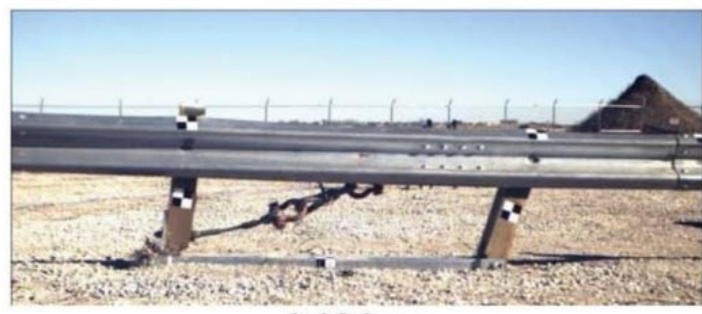

$0.086 \mathrm{sec}$

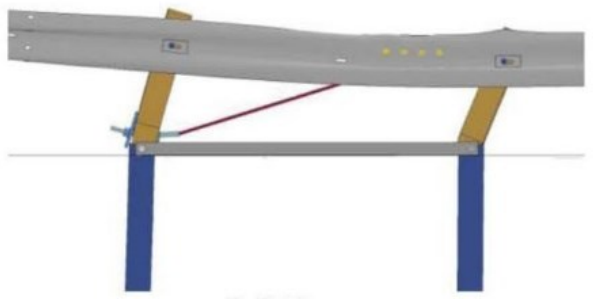

$0.040 \mathrm{sec}$

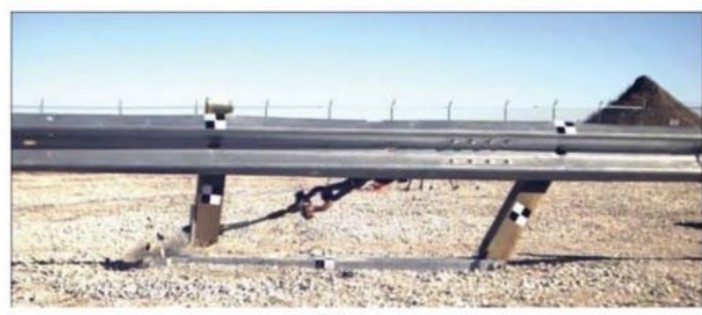

$0.100 \mathrm{sec}$

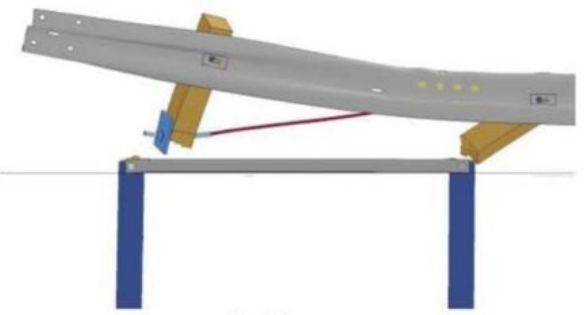

$0.60 \mathrm{sec}$

Fig. 10. Time-sequential images, test and simulation, end-anchorage pull test (DSAP 2). 


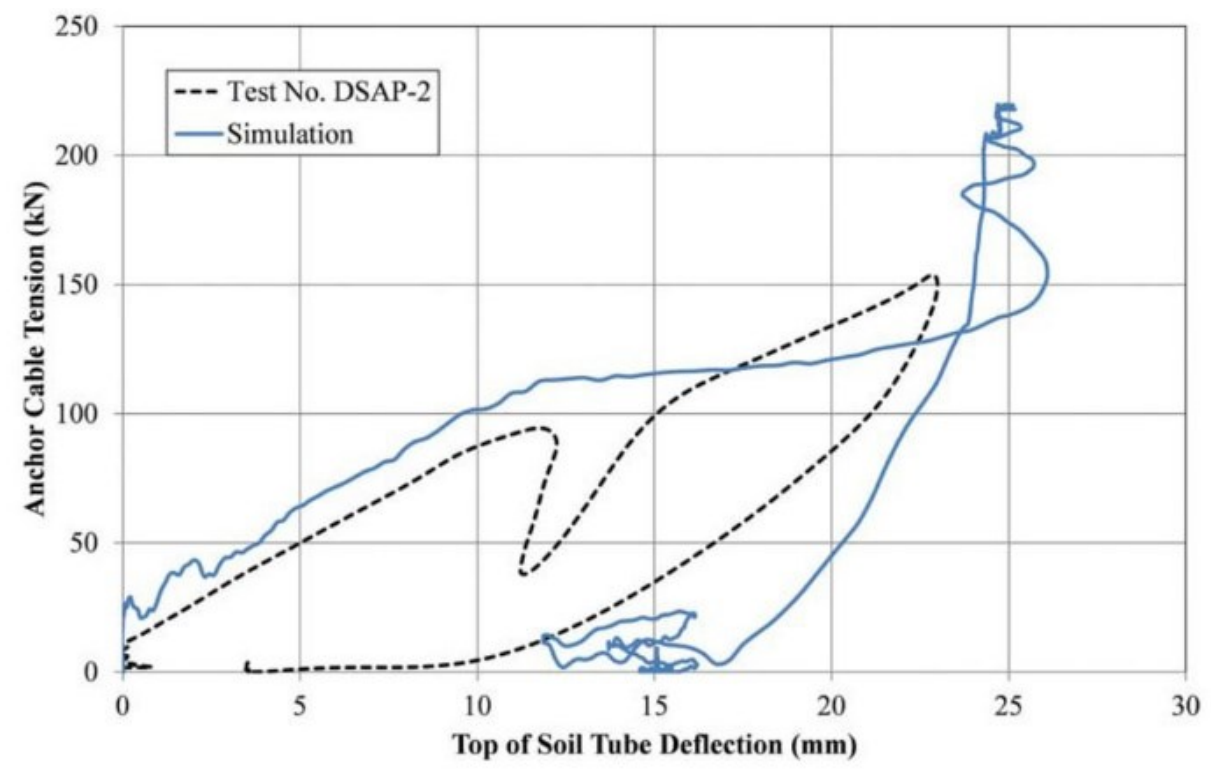

Fig. 11. BCT cable tension and soil foundation tube displacement, test and simulation, end-anchorage pull test (DSAP 2).
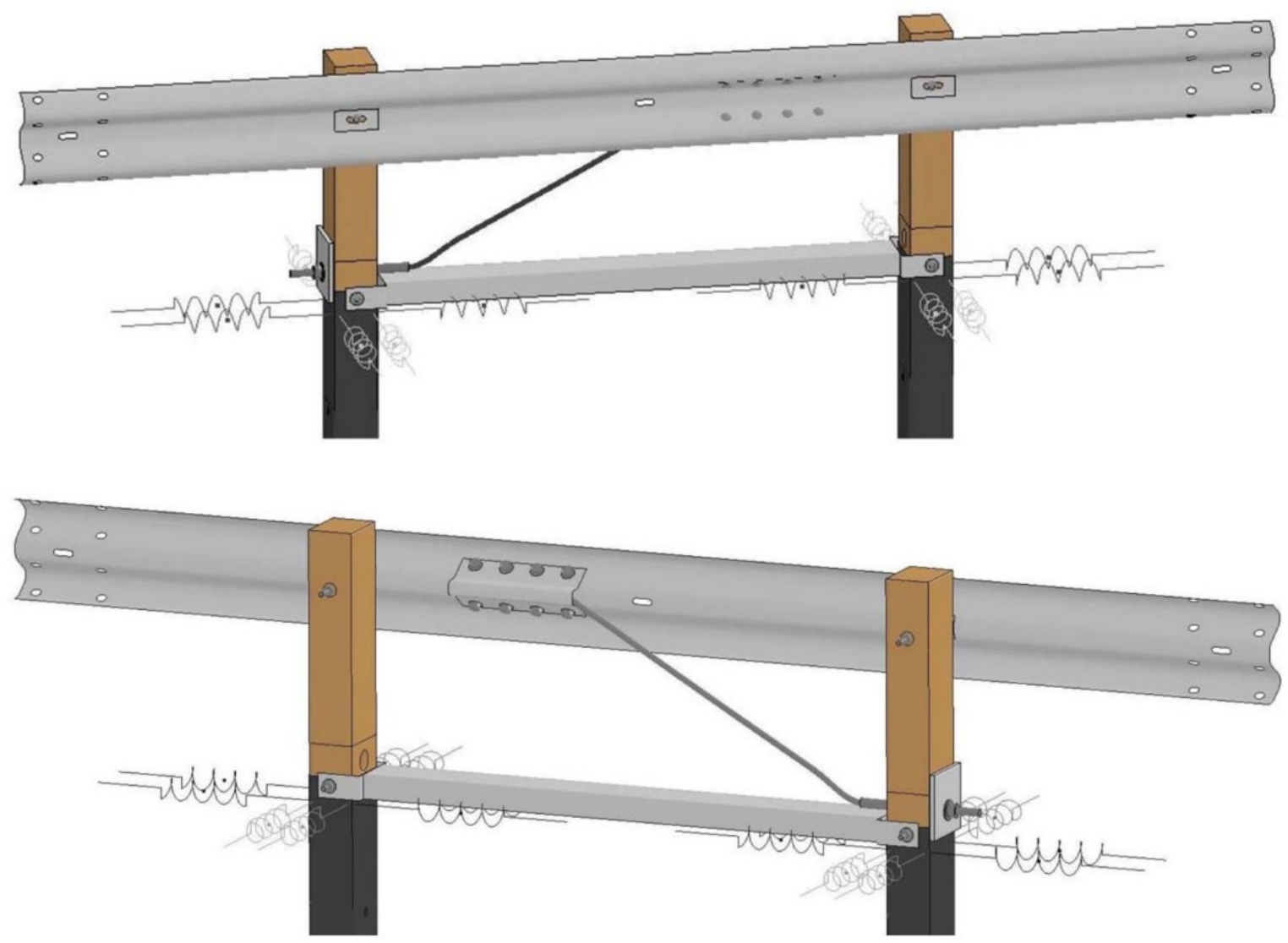

Fig. 12. MGS end anchorage simulation model. 


\section{Tables}

Table 1. Summary of results for MGS end-anchorage component tests and simulations.
MGSEA-1
Simulation

\begin{tabular}{|c|c|c|c|c|}
\hline Maximum Displacement (mm) & \multicolumn{2}{|l|}{165} & \multicolumn{2}{|l|}{173} \\
\hline \multicolumn{5}{|l|}{ 1st Peak Load } \\
\hline Displacement (mm) & \multicolumn{2}{|l|}{56} & \multicolumn{2}{|l|}{51} \\
\hline Load $(\mathrm{kN})$ & \multicolumn{2}{|l|}{193} & \multicolumn{2}{|l|}{163} \\
\hline 2nd Peak LoadDisplacement (mm) & \multicolumn{2}{|l|}{140} & \multicolumn{2}{|l|}{124} \\
\hline Load $(\mathrm{kN})$ & \multicolumn{2}{|l|}{176} & \multicolumn{2}{|l|}{171} \\
\hline \multicolumn{5}{|l|}{ Energy Comparison } \\
\hline 25 mm Deflection $(\mathrm{kJ})$ & \multicolumn{2}{|l|}{0.9} & \multicolumn{2}{|l|}{1.7} \\
\hline $51 \mathrm{~mm}$ Deflection (kJ) & \multicolumn{2}{|l|}{4.2} & \multicolumn{2}{|l|}{5.5} \\
\hline 76 mm Deflection (kJ) & \multicolumn{2}{|l|}{8.4} & \multicolumn{2}{|l|}{$7 \cdot 3$} \\
\hline $102 \mathrm{~mm}$ Deflection (kJ) & \multicolumn{2}{|l|}{11.0} & \multicolumn{2}{|l|}{9.5} \\
\hline \multicolumn{5}{|l|}{ Average Force } \\
\hline $25 \mathrm{~mm}$ Deflection $(\mathrm{kN})$ & \multicolumn{2}{|l|}{35} & \multicolumn{2}{|l|}{68} \\
\hline $51 \mathrm{~mm}$ Deflection $(\mathrm{kN})$ & \multicolumn{2}{|l|}{82} & \multicolumn{2}{|l|}{108} \\
\hline $76 \mathrm{~mm}$ Deflection $(\mathrm{kN})$ & \multicolumn{2}{|l|}{110} & \multicolumn{2}{|l|}{96} \\
\hline 102 mm Deflection (kN) & \multicolumn{2}{|l|}{109} & \multicolumn{2}{|l|}{94} \\
\hline \multicolumn{5}{|l|}{ Calculated Elastic Soil Stiffness } \\
\hline Elastic loading (kN/mm) & \multicolumn{2}{|l|}{3.66} & \multicolumn{2}{|l|}{3.72} \\
\hline & BCTRS-1 & BCTRS-2 & $\begin{array}{c}\text { Nominal Wood } \\
\text { Strength } \\
\text { Simulation }\end{array}$ & $\begin{array}{l}50 \% \text { Stronger } \\
\text { Wood Strength } \\
\text { Simulation }\end{array}$ \\
\hline Maximum Load During Splitting (kN) & 18.1 & 29.8 & $15 \cdot 3$ & $17 \cdot 3^{*}$ \\
\hline Bogie Displacement at Start of Split ( $\mathrm{mm})$ & 122 & 107 & 127 & 108 \\
\hline Modulus of Stiffening $(\mathrm{kN} / \mathrm{mm})$ & 0.083 & 0.239 & 0.081 & 0.107 \\
\hline Energy at Start of Split (kJ) & 1.80 & 2.46 & 1.37 & 1.82 \\
\hline Energy at Completion of Split (kJ) & 2.15 & 2.94 & 2.21 & - \\
\hline $\begin{array}{l}\text { Minimum Post-to-Rail Force } \\
\text { Required to Cause Splitting (kN) }\end{array}$ & 33 & 54 & 27 & 31 \\
\hline
\end{tabular}

* Splitting was arrested and post fractured in weak axis bending.

DSAP-2 Nominal Wood Strength Simulation

\begin{tabular}{lll}
\hline $\begin{array}{l}\text { Maximum Anchor Cable Load (kN) } \\
\text { Maximum Soil Foundation Tube }\end{array}$ & 154 & 222 \\
$\quad$ Deflection - End Post (mm) & 22.9 & 23.9 Maximum Load \\
Total Energy Dissipated (kJ) & & 26.2 Maximum Value \\
Fracture Time - End Post (ms) & 5.40 & 5.13 \\
Fracture Time - Second Post (ms) & 70 & 30 \\
& 40 (crack) & 20 (crack) \\
End Foundation Tube Soil Stiffness (kN/mm) & 70 (rupture) & 30 (rupture) \\
& 7.67 (loading) & 8.30 (loading)) \\
& 10.23 (unloading) & (not calculated for unloading)
\end{tabular}


Table 2. Summary of simulation parameters.

\begin{tabular}{|c|c|c|c|c|}
\hline Component & $\begin{array}{c}\text { Mesh } \\
\text { (kg, mm, ms units) }\end{array}$ & $\begin{array}{c}\text { Nominal Wood } \\
\text { (kg, mm, ms units) }\end{array}$ & $\begin{array}{c}\text { Stronger Wood } \\
\text { (kg, mm, ms units) }\end{array}$ & Quantity \\
\hline $\begin{array}{l}\text { Soil Foundation } \\
\text { Tube }\end{array}$ & 10-mm Shell Elements & $\begin{array}{l}\text { Rigid Steel, Constrained } \\
\text { Against Translation, Twist }\end{array}$ & $\begin{array}{l}\text { Rigid Steel, Constrained } \\
\text { Against Translation, Twist }\end{array}$ & 2 \\
\hline $\begin{array}{l}\text { Soil Equivalency } \\
\text { Spring }\end{array}$ & $\begin{array}{c}2700-\mathrm{mm} \text { Springs per } \\
\text { Side of Foundation } \\
\text { Tube }\end{array}$ & $\begin{array}{c}{ }^{*} \text { MAT_SPRING_- } \\
\text { NONLINEAR_ELASTIC } \\
\text { Tension Yield: } 20 \\
\text { Compresson Yield: }-20\end{array}$ & $\begin{array}{c}{ }^{*} \text { MAT_SPRING_- } \\
\text { NONLINEAR_ELASTIC } \\
\text { Tension Yield: } 20 \\
\text { Compresson Yield: }-20\end{array}$ & 16 \\
\hline BCT Post & 10-mm Solid Elements & $\begin{array}{c}\text { MAT_24 } \\
\left.\text { Density: 6.274(10 }{ }^{-7}\right) \\
\text { Elastic Modulus: } 11.0 \\
\text { Plastic Modulus: } 0.250 \\
\text { Poisson's Ratio: } 0.300 \\
\text { Yield Strength: } 0.0060 \\
\text { Rupture EPS: } 0.080\end{array}$ & $\begin{array}{c}\text { MAT_24 } \\
\left.\text { Density: 6.274(10 }{ }^{-7}\right) \\
\text { Elastic Modulus: } 11.0 \\
\text { Plastic Modulus: } 0.250 \\
\text { Poisson's Ratio: } 0.300 \\
\text { Yield Strength: } 0.0090 \\
\text { Rupture EPS: } 0.074\end{array}$ & 2 \\
\hline BCT Cable & 13-mm Beam Elements & Modified from [16] & Modified from [16] & 1 \\
\hline $\begin{array}{l}\text { Threaded End } \\
\text { of BCT Cable }\end{array}$ & 7-mm Solid Elements & Steel (deformable) & Steel (deformable) & 2 \\
\hline $\begin{array}{l}\text { Swaged Portion of } \\
\text { BCT Cable }\end{array}$ & 7-mm Solid Elements & Rigid Steel & Rigid Steel & 2 \\
\hline Cable Anchor Bracket & 13-mm Shell Elements & Rigid Steel & Rigid Steel & 1 \\
\hline Bearing Plate & 13-mm Solid Elements & Rigid Steel & Rigid Steel & 1 \\
\hline Yoke & 10-mm Shell Elements & Rigid Steel & Rigid Steel & 2 \\
\hline Strut & 10-mm Shell Elements & Steel (deformable) & Steel (deformable) & 1 \\
\hline Vertical Splitting & $\begin{array}{c}\text { Separate, unmerged part } \\
\text { meshes with coincident } \\
\text { nodes }\end{array}$ & $\begin{array}{c}\text { *CONTACT_AUTOMATIC_- } \\
\text { SURFACE_TO_SURFACE_ } \\
\text { TIEBREAK } \\
\text { Option } 6 \text { - Linear Damage with } \\
\text { Crack Surface Separation } \\
\text { Critical Crack Separation: } 4 \mathrm{~mm}\end{array}$ & $\begin{array}{c}\text { *CONTACT_AUTOMATIC_- } \\
\text { SURFACE_TO_SURFACE_ } \\
\text { TIEBREAK } \\
\text { Option } 6 \text { - Linear Damage with } \\
\text { Crack Surface Separation } \\
\text { Critical Crack Separation: } 4 \mathrm{~mm}\end{array}$ & 1 \\
\hline
\end{tabular}

* Loading curve for single soil spring shown below; unloading curve is linear with 4:1 slope 